\title{
Heavy Metals Concentrations in Five Brands of Lip Gloss and Mascara Cosmetics Sold and Used in Calabar, Cross River State, Nigeria
}

\author{
AKPE, MA; ANOZIE, RC; INEZI, FP \\ Department of Pure and Applied Chemistry, University Of Calabar, Nigeria \\ *Corresponding Author Email: akomayeakpe2015@gmail.com
}

\begin{abstract}
This study is evaluated the concentration of some toxic heavy metals present in selected cosmetics sold and used in Calabar, Cross River State, Nigeriausing aFlame Atomic Absorption Spectrophotometer (AAS), VGP 210 (BUCK Scientific) Model. The result revealed that the average concentration of the metals in $\mathrm{mg} / \mathrm{L}$ ranged thus: Cadmium (0.012- 0.046), Chromium (0.002- 0.022), Lead (0.004- 0.024) and Nickel (0.140- 0.416). The concentration of Arsenic and Mercury was not detected, and were considered string variables in this study. From the results, the concentration of the metals detected were within the permissible limit of the World Health Organization (WHO) except Cadmium that was slightly above the WHO limit in one of the samples with a value of $0.046 \mathrm{mg} / \mathrm{L}$. These results indicate that the selected cosmetics used in Calabar contains low amounts of the heavy metals analyzed in this study and may not pose any health risk for now, except that the accumulation of such little amounts over time due to prolonged use of these cosmetics may cause harm.
\end{abstract}

\section{DOI: https://dx.doi.org/10.4314/jasem.v24i7.15}

Copyright: Copyright (C) 2020 Akpe et al. This is an open access article distributed under the Creative Commons Attribution License (CCL), which permits unrestricted use, distribution, and reproduction in any medium, provided the original work is properly cited.

Dates: Received: 16May 2020; Revised: 29June 2020; Accepted: 07July 2020

Keywords: Concentration, Heavy metals, Cosmetics, Calabar

The use of cosmetics as part of routine body care is as old as man himself. The demand for cosmetics from around the globe has increased rapidly due to the growing awareness of the need to beautify the human body (Ullah et al., 2013), likewise the sharp rise in their advertisement in the media (Gondal et al., 2010).Cosmetics can be defined as articles and their components intended to be rubbed, poured, sprinkled or sprayed on, or introduced into, or otherwise applied to, the human body or any part thereof for cleansing, beautifying, promoting attractiveness, or altering the appearance (Ramakant et al., 2014). According to Amits et al. (2017), cosmetics have constituted a part of routine body care right from the dawn of civilization, not only by the upper strata of society but also by middle and low class people. The last few decades have witnessed a big boost in cosmetic industries, by the production of the various types of cosmetics which are needed for the care and beautification of the skin, hair, nails, teeth etc. Body care products comprises of creams, beauty soaps, talcum and face powders, lotions, shampoos, hair oils, hair dyes, hair colors, perfumery items, lipsticks, shaving creams, body lotions, tooth paste etc. Although beauty consciousness of people has increased the demand for cosmetics in the market, the side effects as well as health consciousness of people has caught the attention of clinicians and researchers to find out the probable reason behind their side effects. Heavy metals contamination is one of the important reasons behind the same problem, as metals like lead, cadmium and mercury are common contaminants in various cosmetic products (Al-Saleh et al., 2009). A heavy metal has a specific gravity of 5.0 or greater and is usually poisonous. The term heavy metal however, is often widely applied to include other potentially toxic elements even if they do not meet up with the apt chemical definition (Hardy et $a l ., 2008$ ). They include transition metals or some metalloids like those considered in this study. Dermal exposure of heavy metals is considered to be the most significant route for cosmetic products because majority of the cosmetics are applied externally. The absorption of heavy metals depends on some factors like the physical and chemical properties of the mixture. However, dermal exposure of heavy metals is often considered minimal. According to Sainio et al. (2000), oral exposure can also take place especially for cosmetics used in and around the mouth, as well as from hand to mouth contact after exposure to cosmetics containing heavy metals but exposure by inhalation is considered to be negligible. Thus, cosmetics like tooth paste, mouth wash, lips gloss and lipsticks are most likely to lead to oral exposure of heavy metals or other contaminants. Cosmetics like the skin lightening types are used widely in most 
African countries, especially by women. When these products are used for a long time, on a large body surface and under hot humid conditions, cutaneous absorption is enhanced. The complications can be very serious as some studies have shown an association between some ingredients of cosmetics and various health problems (Nohynek et al., 2010). The pattern of accumulation of these metals can be altered by some physiological changes. Majority of the metals acts as endocrine disrupters interfering with the hormonal system (Bergamaschi et al., 2007).

Heavy metals occurring in the natural environment (waters, soil, rocks) are found in trace amounts in raw materials used in the cosmetic industry. They can be desirable ingredients (e.g. dyes) or undesirable in many cosmetics. Metallic impurities posing a threat to the health of consumers are inter alia, particularly harmful elements such asLead, Nickel, Cadmium, Mercury etc. Although their content in cosmetics is prohibited o restricted in some countries, there are no regulations in this regard in many countries. Apart from the toxic trace metals, elements like Iron, Copper and Zinc are necessary, yet dangerous in excessive amounts, may also be present in cosmetics. Contamination of cosmetic preparations with heavy metals occurs in the production process or as a result of inadequate purification of natural raw materials used as ingredients (Boccab et al., 2014). Due to the bogus nature cosmetics in developing and underdeveloped countries like Nigeria, the facial cosmetics are sometimes being sold under thebrand name of reputable national and international companies in both open markets and superstores in the country.

Several researches have shown the presence of heavy metals in a wide range of cosmetics in different parts of the world. A study by (Pergrino et al., 2011) revealed Mercury in alarming levels ranging from 878 to $36000 \mathrm{ppm}$ as recorded in six (6) out of sixteen (16) samples when Mexican skin lightening creams were analyzed. Another study which specifically assessed heavy metals $(\mathrm{Pb}, \mathrm{Ni}, \mathrm{Cu}, \mathrm{Co}, \mathrm{Cr}, \mathrm{Mn}, \mathrm{Zn}, \mathrm{Cd})$ in some eye shadows imported from China into Nigeria reported the presence of these metals in varying concentrations but all the metals assessed were beyond permissible except Chromium (Omalaoye et al.,2010).Researchers in California found that most of the tested lips products contain high concentrations of Titanium and Aluminium, they had detectable Manganese, Lead was detected in $75 \%$ of samples tested and $47 \%$ of the samples had a concentration higher than the FDA-recommendedmaximum level of $0.1 \mathrm{ppm}$ for $\mathrm{Pb}$ in candy likely to be consumed by small children while Chromium and Nickel were present in almost all the samples with concentrations of 9.27 and 9.73ppm respectively (Liu et al., 2013).In a study conducted in Kano State, Nigeria, a total of skin powder products were sampled from Sabon Gari (Bata) market with the aim of detecting the presence of Cadmium and Chromium and all the metals detected in all the samples, even though at different concentrations $(\mathrm{P} \leq 0.05)$, with the concentration of Chromium was lower when compared to Cadmium (Imam and Saidu, 2015). Also, an assessment by WHO reported that mercury in skin lightening creams and soaps that are commonly used in Asian and Central African nations is potentially dangerous as they have serious side effect and can be fatal. Mercury present in fairness cream can cause anxiety, depression, nerve damage, reduces skin resistance to infections, can cause seizures, numbness and even memory loss (WHO, 2008).

Due to the high global demand for cosmetics, their safety has become a great concern and has attracted the attention of researchers, toxicologist, and regulators, with the common objective of ensuring the safety levels of ingredients in the products (Al-Saleh et al., 2011). This study was undertaken with the view to determine the concentration of selected heavy metals in some cosmetics used in Calabar in order to ascertain their quality and safety with respect to heavy metals contamination. This is because Calabar is one of the leading cities that patronize cosmetic products in Nigeria and its inhabitants, especially women known for cleanliness and beauty consciousness. Besides, there is a literature gap concerning cosmetic products used in this study as they have not been studied and reported in Nigeria among others like body creams, beauty soaps, face powders, eye shadow colors etc. Thus, the need to safeguard the health of the people against toxic heavy metals in adulterated or fake cosmetics becomes imperative. The objective of this paper is to report the concentration of $\mathrm{As}, \mathrm{Cd}, \mathrm{Cr}, \mathrm{Pb}$, $\mathrm{Hg}$ and $\mathrm{Ni}$ evaluated in five different brands of lip gloss and Mascara cosmetics sold and used in Calabar, Cross River State, Nigeria.

\section{MATERIALS AND METHODS}

The materials used include Electrical weighing balance, measuring cylinder, microwave oven, heating mantle, beakers, conical flask, watch glass, filter paper, distilling flask, funnel and Atomic Absorption Spectrophotometer (AAS) for apparatus, and Trioxonitrate (V) acid $\left(\mathrm{HNO}_{3}\right)$, Tetraoxosulphate (VI) acid, Hydrochloric acid $(\mathrm{HCl})$ and distilled water for reagents. The samples used were five (5) lip glosses and Mascara,six (6) samples in all. 
Sample Collection: Five (5) most popular brands of lip glosses and Mascara were collected (purchased) from Marian market in Calabar. They were labeled as follows: SP, VM, RM, SK, MG and FB. The samples were chosen based on their application on the lips (mouth) or face and their possibility of oral exposure among other means of exposure. In addition, there is a literature gap concerning Lip glosses and Mascara used in this study as they have not been studied and reported in Nigeria among other cosmetics like body creams, lipsticks, beauty soaps, face powders, eye shadow colors etc.

Sample Preparation: The samples were dried in an oven at $100{ }^{\circ} \mathrm{C}$ for about 30 minutes and $1.0 \mathrm{~g}$ of each sample was weighed into an acid washed beaker. Each sample in a separate distilling flask was placed in a fume cupboard was digested by adding $20 \mathrm{~mL}$ of aqua regia (mixture of concentrated $\mathrm{HCl}$ and $\mathrm{HNO}_{3}$, in the ratio $3: 1$ ) and $5 \mathrm{~mL} \mathrm{H}_{2} \mathrm{SO}_{4}$. After the bubbling and evolution of gases was over, the digest in each flask was covered with a watch glass and heated at $100{ }^{\circ} \mathrm{C}$ for about 30 minutes when no fumes were observed. The heating mantle was turn off and the sample left to cool. After cooling, $100 \mathrm{~mL}$ of distilled water was added to the digest, stirred and filtered into a conical flask using a Whatman filter paper. The filtrate was used for heavy metals analysis in the Atomic Absorption Spectrometer (AAS).

Elemental Analysis: Each of the samples were analyzed for the selected heavy metals namely; Arsenic (As), Cadmium (Cd), Chromium (Cr), Mercury $(\mathrm{Hg})$, Lead $(\mathrm{Pb})$ and Nickel $(\mathrm{Ni})$ using a Flame Atomic Absorption Spectrometer (AAS), VGP 210 (BUCK Scientific) Model.

\section{RESULTS AND DISCUSSION}

The results in Table 1 revealed that Arsenic and Mercury were not detected in any of the six (6) cosmetic products sampled and are considered string variables in this study. Cadmium, Chromium and Nickel were detected or present in all the six samples, while Lead was detected or present in five (5) out of the six samples, and not detected in one sample labeled VM to be specific. The results also show that the mean concentration of $\mathrm{Cd}$ in $\mathrm{mg} / \mathrm{L}$ ranged from 0,012 to 0.046 , Cr ranged from 0.004 to 0.022 , Ni ranged from 0,140 to 0.416 and $\mathrm{Pb}$ ranged from 0.004 to 0.024.Thus, the mean concentration of the metals in cosmetics studied is in the order: $\mathrm{Ni}>\mathrm{Cd}>\mathrm{Pb}>\mathrm{Cr}>$ As $>\mathrm{Hg}$. These results indicates that the cosmetic products used in this study are actually contaminated with 4 out of the 6 heavy metals analyzed namely; $\mathrm{Cd}$, $\mathrm{Cr}$, Ni and $\mathrm{Pb}$. However, $\mathrm{Cr}$ was within the World Health Organization(WHO) permissible oral exposure limit of $0.05 \mathrm{mg} / \mathrm{L}$ in all the samples. $\mathrm{Pb}$ was at the maximum permissible limit of oral exposure of 0.01 set by WHO (2008), except in one sample out the 5 where it was slightly higher with a value of 0.024 $\mathrm{mg} / \mathrm{L}$. Cd was at its permissible limit of $0.01 \mathrm{mg} / \mathrm{L}$ in 2 sample out of 6 and exceeded the limits in 4 samples, while Ni exceed the WHO oral exposure limit of 0.07 $\mathrm{mg} / \mathrm{L}$ in all the 6 samples. $\mathrm{Cd}$ and $\mathrm{Ni}$ were considered to have exceeded the oral exposure limits of WHO which are applicable mostly to food and not dermal exposure. Since these cosmetics are not ingested but applied externally, they may not pose any risk or cause immediate harm like oral exposure. Also, the concentration of these metals can be considered low by percentage composition of the total quantity of the formulation of these cosmetics.Despitethis, accumulation of these metals by absorption through the skin due to prolong use of these cosmetics may lead to skin reaction, cancer and other problems over time. According to Muhamad et al. (2011), continual exposure to even low levels of these toxic metals in cosmetic products may pose potential health risks. It is possible that skin allergy contact dermatitis may increase as result of the presence of heavy metals cosmetics.

Table 1: Mean concentration of heavy metals in $\mathrm{mg} / \mathrm{L}$ in some cosmetics used in Calabar, Cross River State of Nigeria

\begin{tabular}{llllllll}
\hline S/No. & Sample ID & As & Cd & Cr & Hg & Ni & Pb \\
\hline 1. & MG & BDL & $0.016 \pm 0.004$ & $0.004 \pm 0.002$ & BDL & $0.140 \pm 0.012$ & $0.004 \pm 0.002$ \\
$\mathbf{2 .}$ & FB & BDL & $0.032 \pm 0.005$ & $0.002 \pm 0.001$ & BDL & $0.304 \pm 0.020$ & $0.018 \pm 0.004$ \\
3. & SK & BDL & $0.064 \pm 0.010$ & $0.012 \pm 0.003$ & BDL & $0.362 \pm 0.025$ & $0.012 \pm 0.003$ \\
4. & VM & BDL & $0.012 \pm 0.003$ & $0.018 \pm 0.003$ & BDL & $0.416 \pm 0.031$ & BDL \\
$\mathbf{5 .}$ & SP & BDL & $0.022 \pm 0.004$ & $0.022 \pm 0.004$ & BDL & $0.318 \pm 0.015$ & $0.016 \pm 0.004$ \\
$\mathbf{6 .}$ & RM & BDL & $0.046 \pm 0.010$ & $0.014 \pm 0.003$ & BDL & $0.326 \pm 0.021$ & $0.024 \pm 0.004$ \\
\hline \multicolumn{7}{c}{$N / B$. Values reported in Mean $\pm S D$ format, with $N=3}$.
\end{tabular}

These results also show that the mean concentration of heavy metals in the cosmetics used in Calabar as analyzed in this study are far lower than those studied and reported by Pergrino et al. (2011) in Mexico where $\mathrm{Hg}$ ranged between 878 to $36000 \mathrm{ppm}$ in skin lightening creams and in California where Liu et al. (2013) studied 32 lip products and reported that $\mathrm{Cr}$ and $\mathrm{Ni}$ were found in almost all the samples with the highest concentration of 9.72 and $9.73 \mathrm{ppm}$ respectively. Comparatively, the cosmetics used in 
Calabar can be considered to be of better quality in terms of heavy metals contamination.

The source of these metals in cosmetics could be as result of their presence in the raw materials or ingredients used in their manufacture as impurities because they are not usually listed on their labels as ingredients. This is supported by Ayenimo et al. (2010) who stated that impurities are not intentionally added to the product but are by-products of the manufacturing process due to the breakdown of ingredients or an environmental contamination of raw materials. The persistence of heavy metals in the environment naturally in rocks, soil and water causes them to be present in the manufacture of pigments and other raw materials utilized in different industries including cosmetics. The lack of adequate testing and quality control analysis by most manufacturers and the regulatory oversight by the relevant government agencies is also responsible for the contamination of these cosmetics, as it is possible that some of the companies may not be aware that their products are contaminated with these toxic metals. However, the accumulation of these metals by absorption through the skin due to prolong use of these cosmetics may lead to skin reaction, cancer and other problems over time. Thus, pre- testing of raw materials and post production quality control test against heavy or toxic metals contamination is recommended for the manufacturing companies while regular inspection, monitoring and evaluation as well as public awareness campaign by relevant government regulatory agencies is recommended to safeguard the health of the people.

Conclusion:This study revealed that Arsenic and Mercury were not detected in most of the lip glosses and mascara (cosmetics) used in Calabar, but contaminated with certain amounts of other heavy metals like $\mathrm{Cd}, \mathrm{Cr}, \mathrm{Ni}$ and $\mathrm{Pb}$, with $\mathrm{Cd}$ and $\mathrm{Ni}$ as the leading contaminants, exceeding the WHO permissible oral exposure limits but could be considered low by percentage composition of the formulation of the cosmetics or dermal exposure. They may not pose any risk or cause immediate harm as they are not directly ingested but applied externally.

Acknowledgement: The authors wish to acknowledge and appreciate the support/ contribution of Mr. Emmanuel Obule Abang towards the success of this study.

\section{REFERENCES}

Al-Saleh, I; Al-Enazi, S; Shinwari, N (2009). Concentration of heavy metals in cosmetic products. J. of Regul. Toxicol.Pharmacol. (54):105-113.
Al-Saleh, I; Al-Enazi, S (2011). Trace metals in Lipsticks. J. of Toxicol. Environ. Chem. 93(6):1149-1165.

Amit, SC; Rekha, B; Atul, KS; Sharad, SL; Dinesh, KC; Vinayak, ST (2010). Determination of Lead and Cadmium in cosmetic products. $J$. of Chemical and Pharmaceut. Res. 2(6):92-97

Ayenimo, JG; Yusuf, AM;Adekunle, AS (2010). Heavy metal exposure from personal care products. Bull. of Environ. Contaminat.Toxicol. 84(1):8-14

Bergamaschi, L; Izzio, ER; Giaver, IG; Loppi, MS; Menne, T (2007). Comparison between the accumulation capacities of four Lichen species transplanted to an Urban site. J. of Environ. Pollut.(148):468-476

Bocca, B; Pino, A; Alimonti, A; Forte, G (2014). Toxic metals contained in cosmetics: A status report.

ofToxicol.andpharmacol.(68):447-467

Regulat.

Gondal, AM; Seddigi, ZS; Nasr, NM; Gondal, B (2010). Spectroscopic detection of health hazardous contaminants in Lipstick using Laser induce break down spectroscopy. $J$. of Hazard.Materi. (17):726-732

Hardy, DH; Myers, J; Strokes, J (2008). Heavy metals in North Carolina soils: Occurrence and significance.North Carolina, USA, Agronomy Division, Dept. of Agriculture and Consumer Service.

Imam, TS; Saidu, BM (2015).Detection of some toxic metals in selected brand of skin powders sold in Kano metropolis market, Northern Nigeria. $J$. Environ. Sci., Toxicol. Food Tech.(5):59-66.

Liu, S; Hammond, SK; Rojas-cheatham, A (2013). Concentration and potential health risks of metals in Lipstick products. Environ. Health Perspect. 121(6):705-710

Muhamad, D; Nasir, F; Sumari, R.A; Ismail, SM; Omar, NA (2011). Characterization of heavy metal content of indoor dust.Asian J. Environ. Behav. Stud. 2(6):53-60.

Nohynek, GJ; Anignac, E; Re, T; Toutain, H (2010). Safety assessment of personal care products/ 
cosmetics and ingredients. J. of Toxicol. Appl.Pharmacol. (243):239-259.

Omolaoye, JA; Uzairu, A; Gimba, CE(2010). Heavy metals assessment of some eye shadow product imported into Nigeria from China. Archives of Appl. Sci. Res. (2):76-84

Pergrino, CP; Moreno, MV; Miranda, SV; Rubio, AD; Leal, L (2011). Mercury levels in locally manufactured Mexican skin lightening creams. Inter. J. of Environ. Res.and Pub. Health,(8):2516-2523

Ramakant, S; Poornima, S; Sapna, J (2014). Heavy metals in cosmetics. Centre for Science and Environment. 41, Tughlakabad Institutional Area, New Delhi 110062
Saino, E; Jolanki, R; Hakala, E; Kanerva, I (2000). Metals anArsenic in eye shadows. $J$. of Contact Dermatitis, 42(1):5-10

Ullah, H; Noren, S; Fozia, M; Rehman, A; Waseem, A; Zubair, S Adnan. M; Ahmad, I (2013). Comparative study of heavy metal content in cosmetic products of different countries marketed in Khyber Pukhtunhwa, Pakistan. Arab J.Chem. 10(1):8-10

WHO/UNEP (2008). Guidance for identifying populations at risk from mercury exposure. Geneva, World Health Organization. www.who.int./entity/FoodSafety/Publications/ch em./mercury. (Accessed March, 2020). 